\title{
PERCEPÇÃO AMBIENTAL DA COMUNIDADE DO ENTORNO DO PARQUE NATURAL MUNICIPAL BARÃO DE MAUÁ, MUNICÍPIO DE MAGÉ, RJ
}

\author{
Vanessa Messias da Silva ${ }^{1}$ \\ Bruno Torres Braga da Silva ${ }^{2}$
}

\section{Resumo}

As unidades de conservação (UCs) do grupo de proteção integral têm como objetivo básico a manutenção dos ecossistemas livres de alterações causadas por interferência humana. Um dos ambientes de grande relevância histórico-social e ecológica do município de Magé é o manguezal, que teve como estratégia para sua conservação a criação do Parque Natural Municipal Barão de Mauá, localizado no $5^{\circ}$ Distrito. Este estudo teve por objetivo conhecer a percepção ambiental sobre a importância do ecossistema manguezal, bem como determinar o nível de conhecimento e envolvimento da comunidade residente no entorno em relação ao parque municipal. Desta forma, procurou-se determinar as principais necessidades para a efetivação da gestão participativa da UC. Os resultados demonstraram o pouco envolvimento da população com as questões pertinentes ao parque, como a sua criação, vantagens e restrições de uso, indicando a necessidade de estabelecimento de ações, como a educação ambiental, para a integração da comunidade com a UC.

Palavras Chave: Município de Magé/RJ; parque natural municipal; percepção ambiental.

\begin{abstract}
Conservation area of integral protection group has to basic objective the ecosystem maintenance free of changes caused by human interference. One of the environments of great relevance historical, social and ecological of Magé city is the mangrove, which had for its conservation strategy the creation of the Municipal Natural Park Barão de Mauá, located in the 5th District. This study aimed to know the environmental perception, as well as determine the level of knowledge and involvement of the community residing around the Municipal Natural Park Barão de Mauá with the same, and to evaluate the perception of the population regarding the importance of the mangrove ecosystem. Thus, we sought to determine the main requirements for effective participatory management of this Conservation area. The results showed less involvement of the population with issues relevant to the park, with its creation, advantages and restrictions, indicating the need for establishment of actions, such as environmental education, to community integration with the Conservation area.
\end{abstract}

Keywords: Municipality of Magé/RJ; natural park; environmental perception.

\section{Introdução e caracterização da área de estudo}

A Lei $n^{\circ}$ 9.985/2000 que institui o Sistema Nacional de Unidades de Conservação (SNUC) define Unidade de Conservação (UC) como um espaço territorial com características naturais relevantes, com objetivos de conservação e limites definidos, instituído legalmente pelo Poder Público, estando em regime especial de administração, ao qual se aplicam

\footnotetext{
${ }^{1}$ Secretaria Municipal de Meio Ambiente de Magé - Bióloga - E-mail: vannessamessias@ gmail.com

${ }^{2}$ Secretaria Municipal de Meio Ambiente de Magé - Eng. Florestal - E-mail: brunotbs@ymail.com
} 
garantias adequadas de proteção. As UCs são subdivididas em dois grupos: uso sustentável (US) e proteção integral (PI).

As UCs de proteção integral têm como objetivo básico a manutenção dos ecossistemas livres de alterações causadas por interferência humana, admitido apenas o uso indireto dos seus atributos naturais (BRASIL, 2000). A categoria Parque (Nacional, Estadual ou Natural Municipal) tem como objetivo básico:

"a preservação de ecossistemas naturais de grande relevância ecológica e beleza cênica, possibilitando a realização de pesquisas científicas e o desenvolvimento de atividades de educação e interpretação ambiental, de recreação em contato com a natureza e de turismo ecológico." (BRASIL, 2000)

Magé é um município importante do ponto de vista ambiental, pois está inserido dentro do bioma Mata Atlântica (IBGE, 2004), apresentando diversos remanescentes florestais e de ecossistemas associados, como o manguezal e a restinga, que são parcialmente distribuídos ao longo de sua amplitude altimétrica.

No caso do manguezal, trata-se de um ecossistema de grande relevância históricosocial e ecológica no município. É encontrado na zona costeira e característico de regiões tropicais e subtropicais ocupando áreas entre marés. É formado por vegetação lenhosa, adaptada as condições limitantes de salinidade, substrato lodoso e pouco oxigenado e frequente submersão pelas marés. Ademais, o ecossistema se destaca pela alta produtividade e diversidade funcional, possuindo elevada importância ecológica, econômica e social (SOARES et al.,2003)

No Brasil, o manguezal é protegido por legislação federal, pela sua importância no ambiente marinho, pois são fundamentais para a procriação e o crescimento dos filhotes de vários animais, bem como ambiente de rota migratória de aves e alimentação de peixes. A principal lei que protege os manguezais é o Código Florestal (Lei no . 12.651/2012), que no inciso VII do Art. 4", define os "manguezais, em toda a sua extensão", como Área de Preservação Permanente (APP).

Em Magé existem oito UCs legalmente instituídas, sendo quatro federais e quatro municipais, formando um grande mosaico que ocupa cerca de $70 \%$ do território. Destas oito UCs, cinco são de uso sustentável e três de proteção integral.

O Parque Natural Municipal Barão de Mauá foi criado a partir do Decreto 2.795/2012, com uma área total de aproximadamente 116,80 hectares, tendo como objetivos:

I- Preservar e recuperar as áreas degradadas existentes do ecossistema do manguezal e a conservação da biodiversidade associada ao bioma da Mata Atlântica;

II- II- Realizar pesquisas científicas;

III- Desenvolver atividades de visitação, recreação, educação e interpretação ambiental, estimulando o desenvolvimento do turismo em bases sustentáveis; 
IV- Proteger e preservar populações de animais e plantas nativas e oferecer refúgio para espécies migratórias, raras, vulneráveis, endêmicas e ameaçadas de extinção de fauna e flora nativas;

V- Assegurar a continuidade dos serviços ambientais prestados pela natureza. (MAGÉ, 2013)

O parque é ocupado totalmente pelo ecossistema manguezal, localizado no fundo da Baía de Guanabara, tendo como limites a foz do Rio Estrela, a Área de Proteção Ambiental da Estrela, o espelho d'água da Baía de Guanabara e as áreas de terra firme e urbanas circundantes do Manguezal (Figura 01). A unidade se localiza no Bairro Ipiranga, $5^{\circ}$ Distrito de Magé (Guia de Pacobaíba).

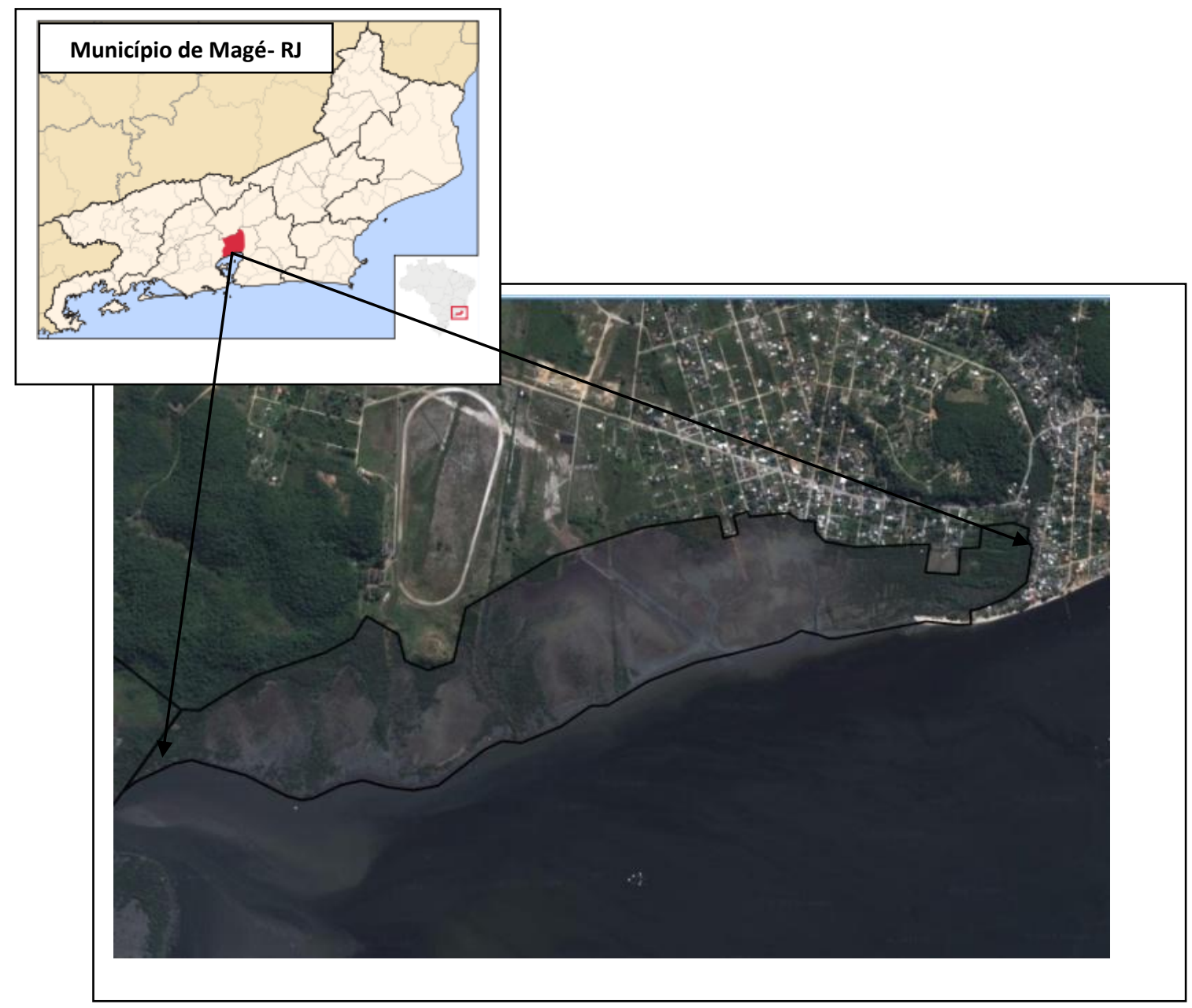

Figura 01. Área do Parque Natural Municipal Barão de Mauá (Imagem Google Earth)

A área do parque veio sofrendo, ao longo dos anos, diversos impactos devido à remoção da vegetação nativa, o despejo de esgotos domésticos dos bairros vizinhos, aterramentos para a expansão urbana, além da contaminação por óleo. Ademais, o derramamento de óleo ocorrido na Baía de Guanabara em janeiro de 2000, causou impactos ambientais negativos e grande depressão econômica na região. 
A partir de 2001 a ONG OndAzul iniciou um projeto de reflorestamento de mangue, intitulado "Mangue Vivo" em áreas do atual Parque Natural Municipal Barão de Mauá. Em pouco mais de dez anos, reflorestou mais 25 hectares de manguezais degradados. Deste projeto partiu a principal iniciativa de transformar esta área em uma UC. A unidade é gerida pela Secretaria Municipal de Meio Ambiente de Magé e ainda não possui conselho gestor, plano de Manejo, além de não dispor de estrutura física ou material para seu funcionamento.

Para se promover a gestão ambiental eficaz são necessários estudos sobre a percepção ambiental dos atores sociais envolvidos direta e indiretamente com a UC. Segundo a Organização das Nações Unidas para Ciência, Educação e Cultura (UNESCO), percepção ambiental é "a maneira pela qual o homem sente e compreende o meio ambiente, em que se é possível interpretar o mundo”. Ao considerar os níveis de percepção ambiental, é possível verificar que os diferentes grupos sociais possuem experiências distintas pela influência de elementos como cultura, faixa etária e nível socioeconômico e que revelam as percepções de diversas formas (GONÇALVES; HOEFFEL,2012).

As UCs precisam ser ativamente monitoradas e gerenciadas para evitar sua deterioração. A partir do momento em que uma área de proteção é legalmente estabelecida, ela deve ser manejada de forma eficaz para manutenção da diversidade biológica. Nesse contexto a gestão participativa é um diferencial valioso. Atualmente, existe um reconhecimento de que o envolvimento das comunidades é essencial para as estratégias de manejo de conservação. Intervenções "de cima pra baixo", através das quais os governos tentam impor seus planos de conservação, precisam estar integradas às necessidades da população, garantindo a melhoria da qualidade de vida e preservação do ecossistema.

São necessárias diversas ações dentro da gestão ambiental para a consolidação da unidade, respeitando seus objetivos da criação. Os processos de gestão de UCs devem considerar a realidade local no intuito de proteger a diversidade biológica e sociocultural (GONÇALVES; HOEFFEL, 2012). Apesar de representar uma medida importante, estabelecer áreas legalmente protegidas através da legislação e da aquisição de terras, por si só, não asseguram a preservação ambiental (PRIMACK; RODRIGUES, 2001).

O objetivo deste trabalho é avaliar a percepção ambiental das pessoas residentes em comunidades localizadas no entorno do Parque Barão de Mauá, bem como determinar o nível de envolvimento com o ambiente. Este conhecimento se constituirá num dado importante estratégico para se definir os melhores caminhos de gestão da UC.

\section{Material e métodos}

O estudo foi realizado em áreas do entorno do parque conhecidas como Olaria e Ipiranga, utilizando-se questionários que foram aplicados aos moradores em dois dias de visita às localidades (Figura 02). 


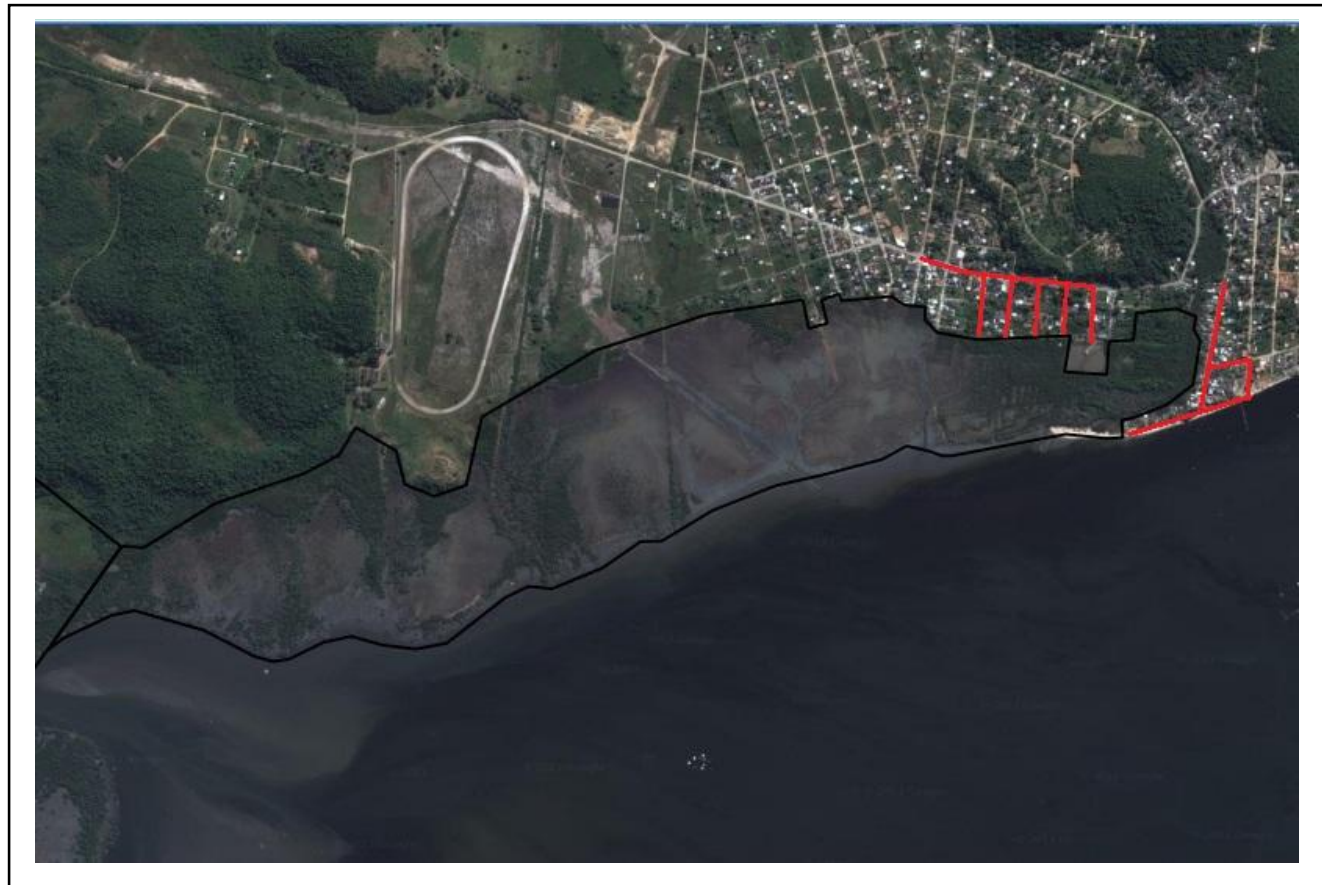

Figura 02. Áreas de pesquisa (em vermelho) e os limites do Parque.

Foram entrevistados 52 moradores, com diferentes faixas etárias e níveis de escolaridade. A tabulação dos dados gerou gráficos que possibilitaram a análise sobre as informações da população a respeito do parque municipal, sua criação, o envolvimento dos moradores na criação da UC e os possíveis benefícios.

\section{Resultados}

A faixa etária amostral variou de 12 até 68 anos, com predominância de adultos. Os dados são apresentados na Figura 03.

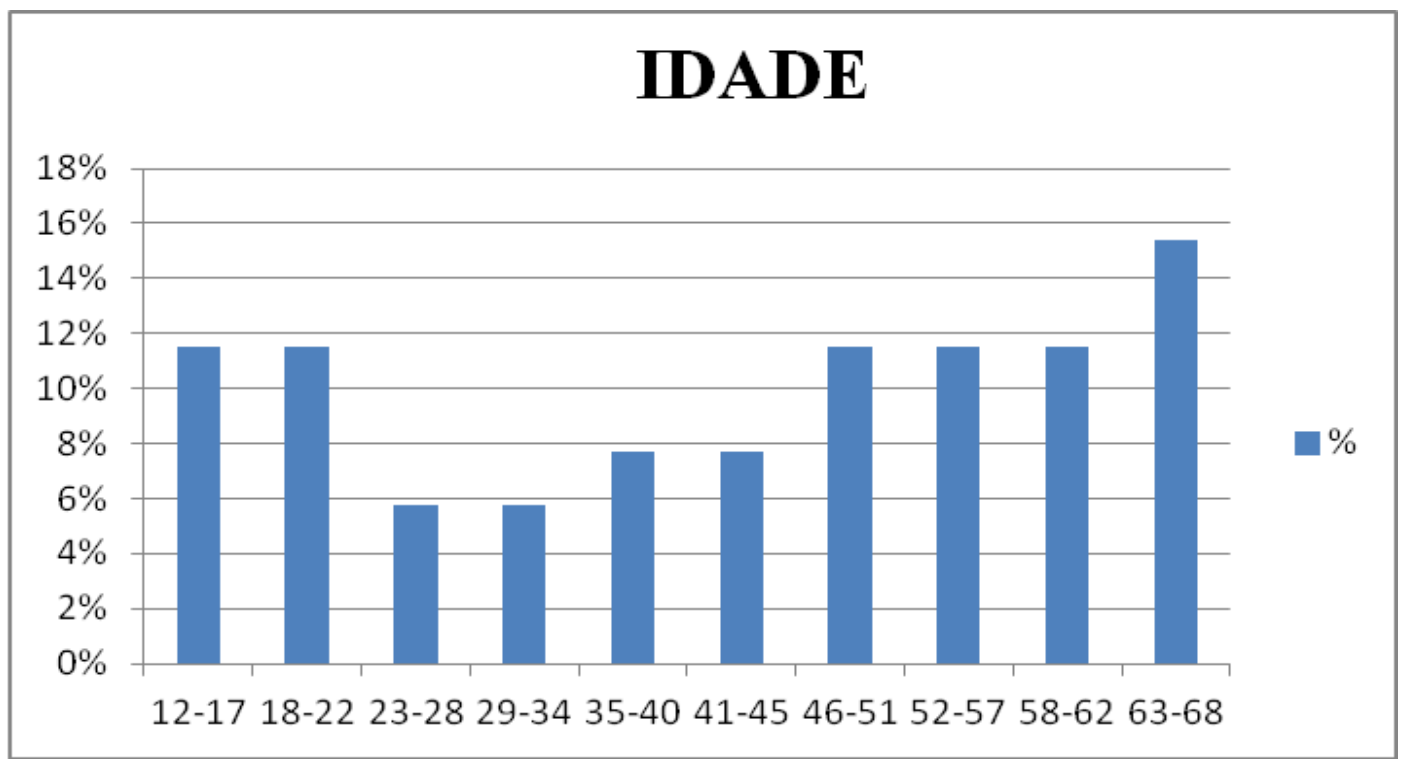

Figura 03. Distribuição por classes de idades dos moradores amostrados. 
Foram colhidas informações sobre o nível de escolaridade havendo distribuição em classes de acordo com o grau de instrução: sem escolaridade, nível fundamental, nível médio e nível superior, sendo que aqueles que possuíam níveis incompletos foram agrupados juntamente com os de mesmo nível completo. Dentre os entrevistados, a maioria tinha o nível fundamental e médio, sendo que nenhum entrevistado possuía nível superior.

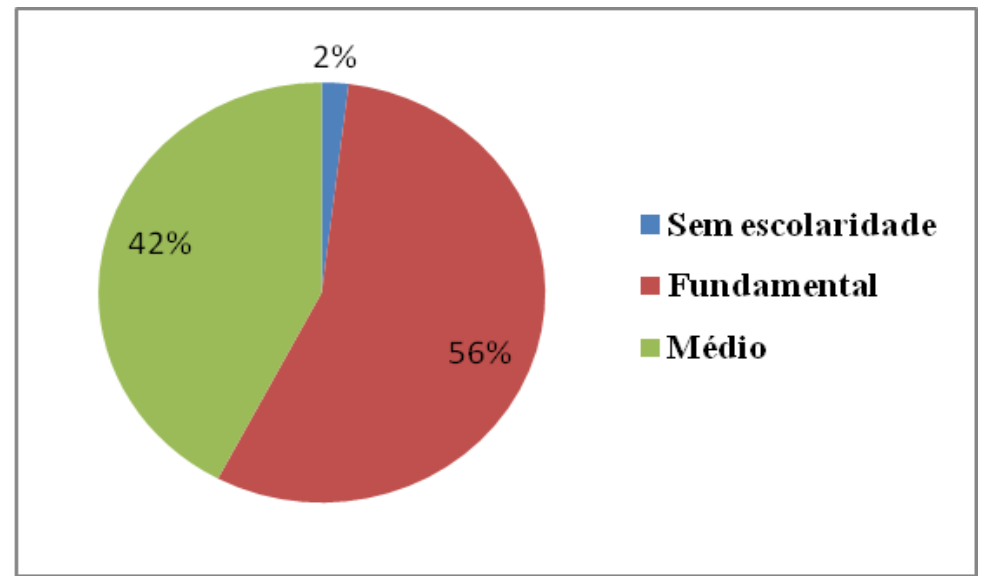

Figura 04. Nível de escolaridade dos entrevistados.

As informações a respeito da faixa etária e o nível de escolaridade refletem o contexto municipal, no qual grande parte da população ainda tem baixo nível de escolaridade, com moradores do entorno aposentados, jovens e desempregados. Com o declínio econômico local, a maior parte da mão de obra assalariada teve de procurar outros locais de emprego, transformando o lugar numa espécie de "cidade dormitório".

Quando questionadas se conheciam alguma Unidade de Conservação, 85\% das pessoas responderam que não e apenas $15 \%$ sim. Dentre as que responderam sim, apenas uma soube informar alguma UC que conhecia, indicando que entre os que responderam sim, muitos não possuíam clareza no que haviam respondido. $\mathrm{O}$ resultado reflete a distância que ainda existe entre o assunto e a realidade da população.

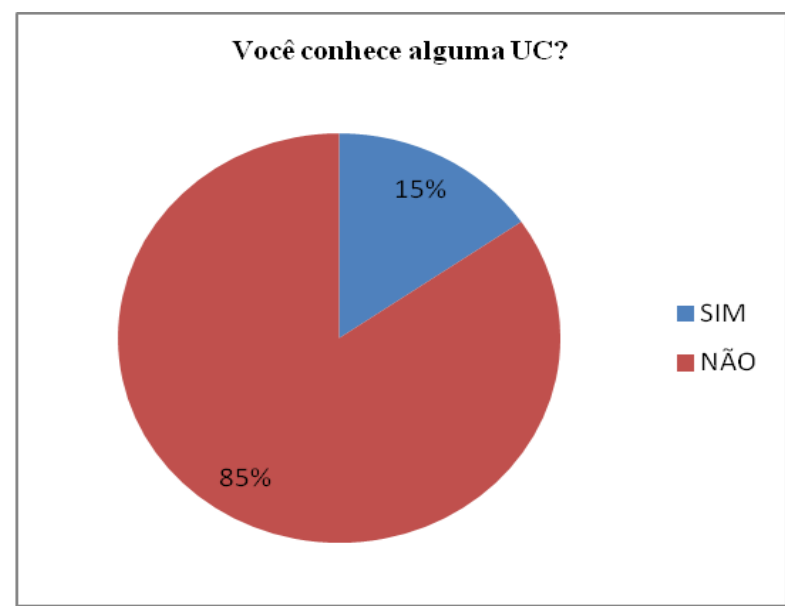

Figura 05. Respostas dos entrevistados à pergunta sobre UCs 
Indagados sobre a presença do Parque no local, grande parte dos entrevistados (79\%) foram categóricos em argumentar que não sabiam da existência e criação da UC de acordo com a Figura 06.

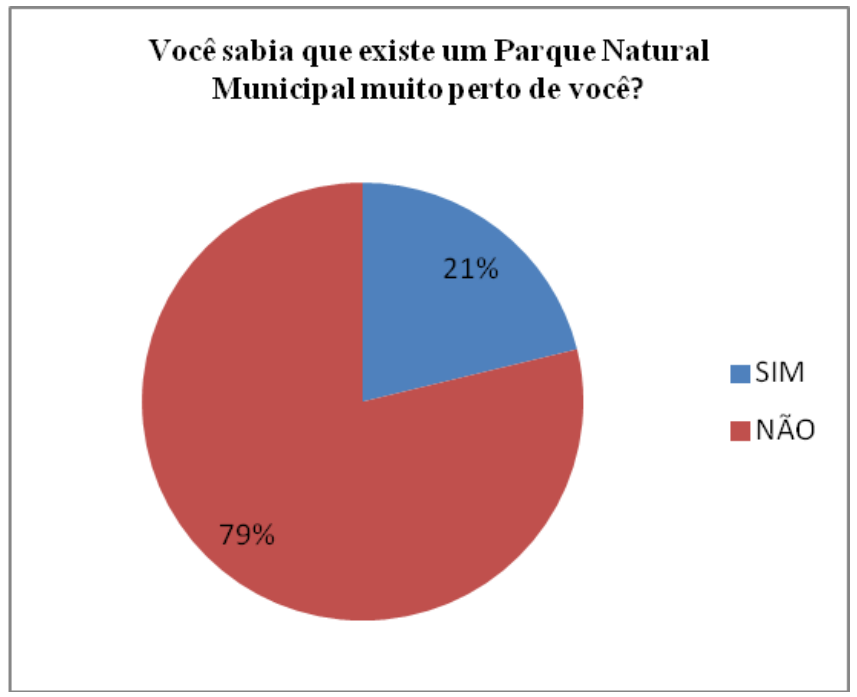

Figura 06. Resposta dos entrevistados sobre o Parque Natural Municipal

Quanto às possíveis restrições de uso e acesso ao parque, 73\% declararam não ter ideia sobre a existência de restrições, conforme pode ser observado na figura 07.

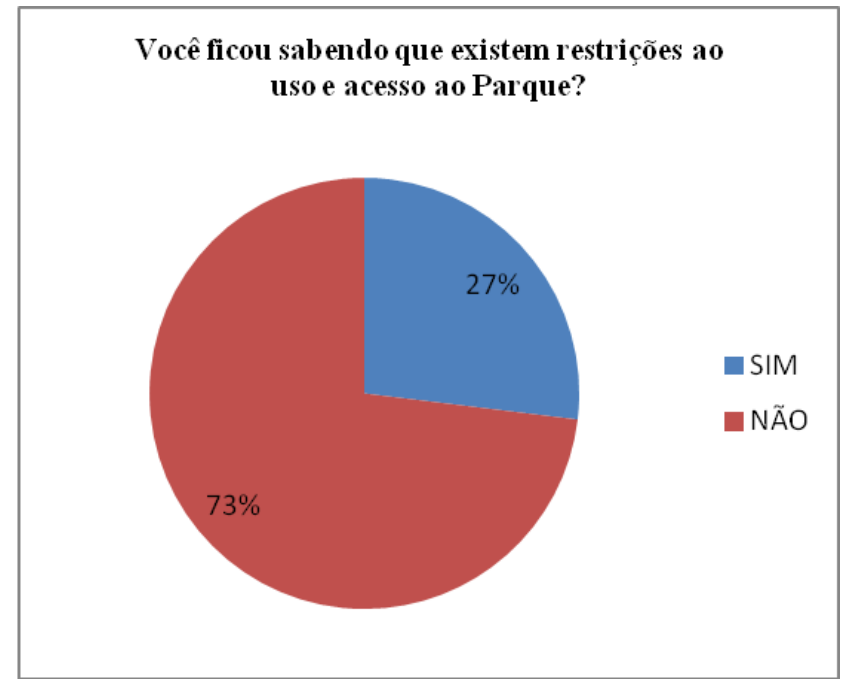

Figura 07. Resposta dos entrevistados sobre as restrições ao parque

Além das restrições, as vantagens de possuir uma UC também foram levantadas, conforme mostra a Figura 08. Quando abordados sobre estas vantagens, as respostas foram divididas em $56 \%$ que desconheciam e $44 \%$ que vislumbravam possíveis vantagens. Os benefícios comentados estavam relacionados às melhores condições de vida para os moradores decorrentes da ampliação do turismo, oportunidade de emprego e renda, além do lazer. Aspectos de preservação e proteção também foram citados com menor intensidade. 


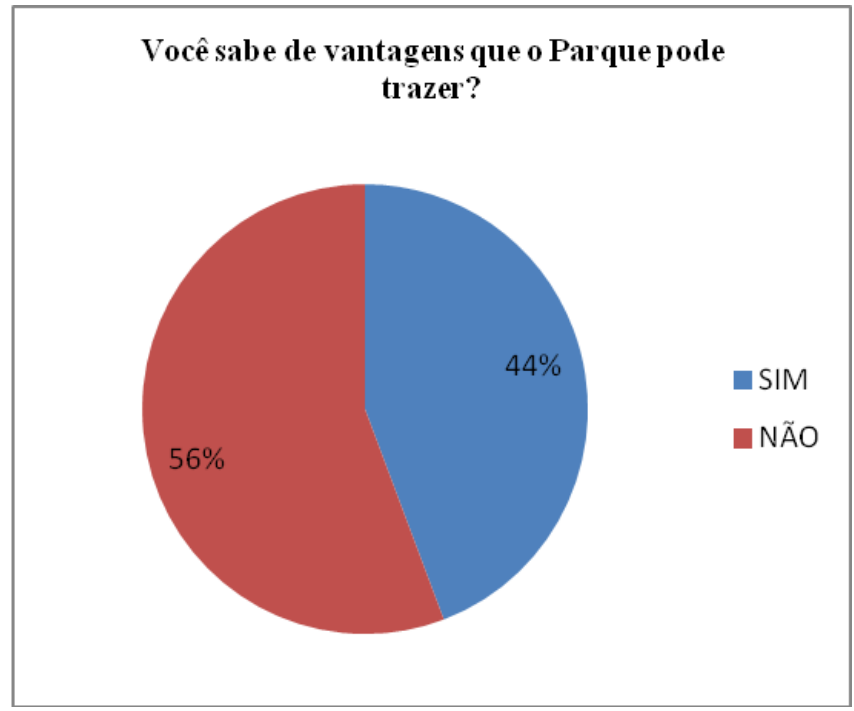

Figura 08. Resposta dos entrevistados sobre as vantagens do parque

Dentro da criação, implantação e gestão de uma UC, cabe ao Poder Público realizar consulta pública visando fornecer informações adequadas e inteligíveis à população local. Ela tem a finalidade de subsidiar a definição da localização, da dimensão e dos limites mais adequados para a unidade.

A consulta pública do parque foi realizada no dia 28 de maio de 2012 com a participação de diversos atores sociais: poder público nas esferas municipal e estadual, organizações não governamentais, associação de pescadores, representantes de outras UCs.

Este assunto foi abordado através da seguinte pergunta: "Você ficou sabendo sobre alguma consulta pública a respeito do parque?". Os resultados são apresentados abaixo de acordo com a Figura 09.

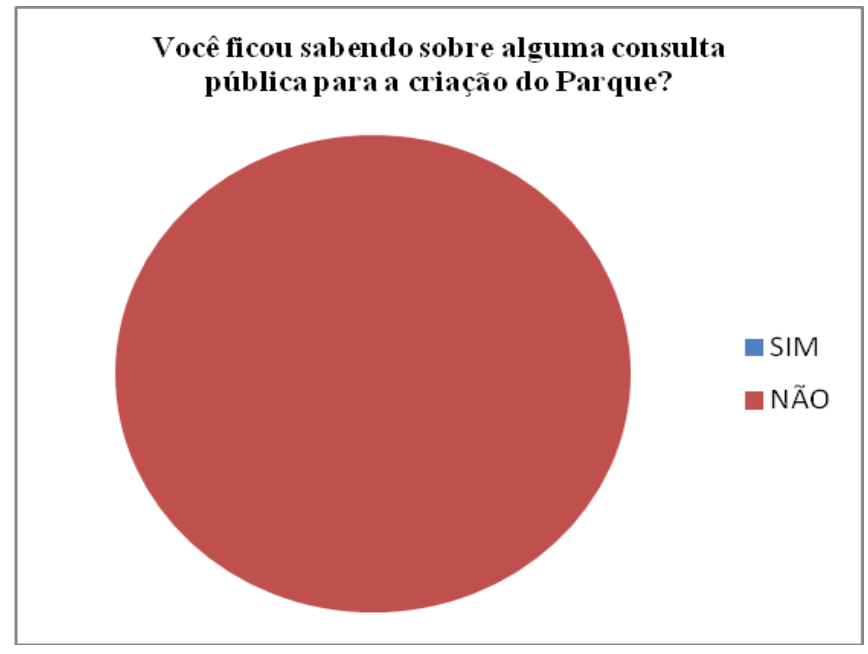

Figura 09. Resposta dos entrevistados sobre a criação do parque

Como pode ser observado, todos os moradores declararam não terem sido informados sobre a consulta pública. É objetivo da consulta pública indicar de modo claro e em linguagem acessível, as implicações para a população residente no interior e entorno da unidade proposta. $\mathrm{O}$ resultado encontrado está intimamente relacionado com as outras 
questões debatidas anteriormente. Se a população está distante do processo de criação do parque, torna-se difícil compreender sua existência, restrições e vantagens. A população ainda se encontra distante de vários processos políticos, não se articula e acaba sem representação diante da tomada de decisões.

Apesar do desconhecimento encontrado por grande parte dos moradores, quando indagados na possibilidade de obter mais informações sobre o parque e seu funcionamento, 96\% dos entrevistados declarou ter interesse, conforme a Figura 10.

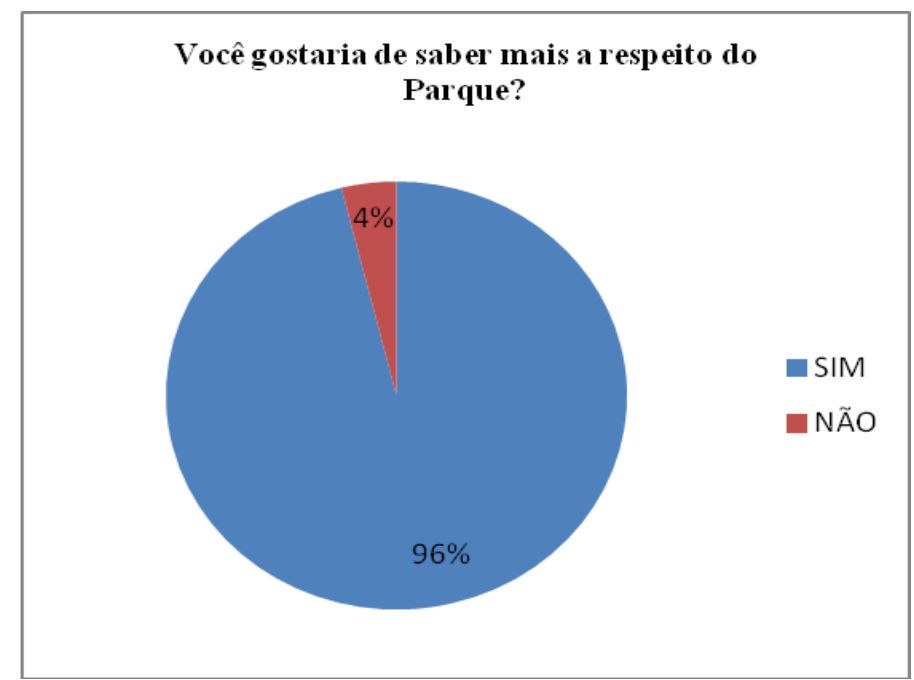

Figura 10. Resposta dos entrevistados sobre informações do parque.

Também houve questionamento sobre a importância do mangue, já que todos os entrevistados são moradores e a maioria deles passou a vida inteira na região. $\mathrm{O}$ resultado apresenta-se na Figura 11. Dos 52 moradores apenas 18 (35\%) declararam não saber a importância do manguezal. Os $65 \%$ restantes descreveram a importância relacionada a diversos fatores com a predominância do item berçário de animais e fonte de renda. Ademais, os dados revelam que a grande relevância ambiental da região ainda é desconhecida pela população.

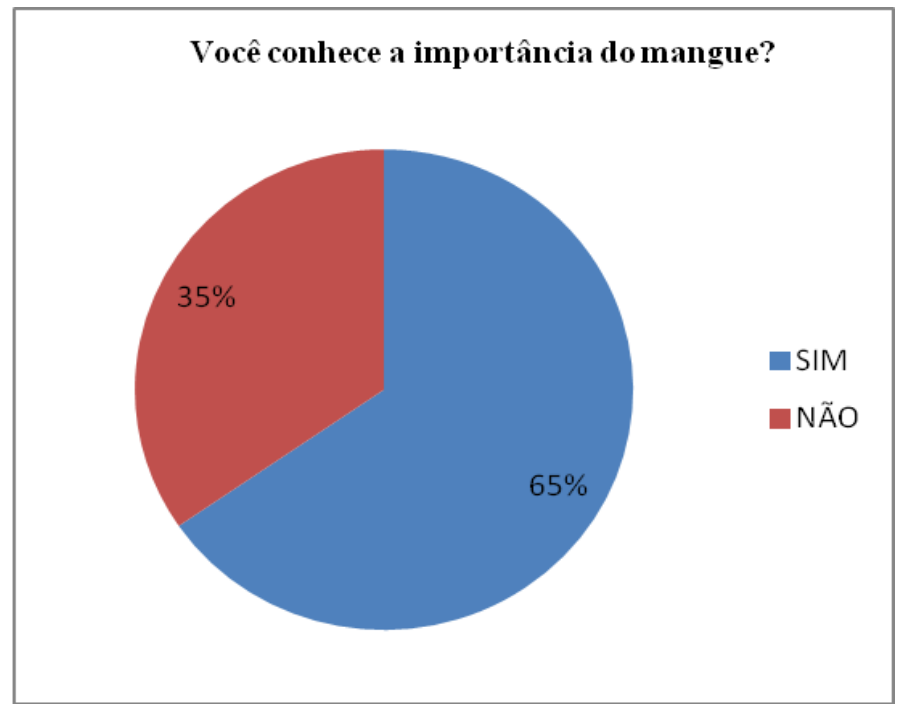

Figura 11. Resposta dos entrevistados sobre a importância do mangue. 


\section{Conclusões}

Cada indivíduo enxerga e interpreta o meio ambiente de acordo com o seu olhar, suas experiências bem como suas expectativas e ansiedades. Se as áreas protegidas puderem gerar alguma forma de vínculo com a população, poderá surgir o sentido de patrimônio comum (NEIMAN; PATRICIO, 2010).

Os resultados demonstram o pouco envolvimento da população com as questões pertinentes ao parque, como a sua criação, vantagens e restrições de uso. Os dados obtidos sobre o conhecimento, restrições e vantagens tornam-se preocupantes quando avaliados juntos a possibilidade de funcionamento da UC, pois, segundo Primack e Rodrigues (2001) se o objetivo de uma área de proteção é apresentado à população local e se a maioria aceita estes objetivos e respeita o parque, então é possível que este consiga manter suas comunidades naturais. Por outro lado, se este objetivo ainda está distante os desafios para o pleno funcionamento da unidade, assegurando a preservação do patrimônio natural, as dificuldades de preservação serão maiores.

Primack e Rodrigues (2001) ainda descrevem que a participação é essencial para a consolidação da UC e o envolvimento da sociedade é um elemento que deve ser incorporado nas estratégias de conservação. Assim, ações articuladas de educação ambiental são necessárias para a sensibilização da população local quanto à importância do ecossistema Manguezal, assegurando a preservação da área do parque e seu uso público responsável.

Uma interação positiva com a sociedade se desenvolve ao ouvir e atender os anseios das pessoas que vivem dentro e no entorno dos parques, desta forma, os resultados encontrados ajudam a determinar o planejamento das ações públicas futuras para a consolidação e administração do parque, indicando que a participação popular nestas ações será imprescindível para que os objetivos do Parque Natural Municipal Barão de Mauá.

\section{Agradecimentos}

Somos gratos aos servidores públicos que diretamente ou indiretamente contribuíram com este trabalho, em especial Regilaine, Alessandro e Brainer, pelo apoio, carinho e disponibilidade. Agradecemos também a toda população entrevistada que com prontidão forneceu as informações aqui apresentadas, objeto e inspiração para nossa pesquisa.

\section{Bibliografia}

BRASIL. (2000) Lei n⿳ 9.985, de 18 de Julho de 2000. Institui o Sistema Nacional de Unidades de Conservação da Natureza.

BRASIL. (2012) Lei no 12.651, de 25 de Maio de 2012. Dispõe sobre a proteção da vegetação nativa.

GONÇALVES, N. M.; HOEFFEL, J. L. M. Percepção ambiental sobre unidades de conservação: os conflitos em torno do parque estadual de Itapetinga - SP. Revista VITAS Visões transdisciplinares sobre Ambiente e Sociedade . Jun, 2012. Disponível em < www.uff.br/revistavitas.htm > Acesso: 10/04/2013. 
IBGE, 2004. Mapa dos biomas brasileiros. Rio de Janeiro: Disponível em <

ftp://ftp.ibge.gov.br/Cartas_e_Mapas/Mapas_Murais/ >. Acesso em: 29 de abril de 2013.

MAGÉ. (2012). Decreto no $\mathbf{2 . 7 9 5}$, de 19 de Outubro de 2012. Dispõe sobre a criação do Parque Natural Municipal Barão de Mauá.

NEIMAN, Z; PATRÍCIO, R. Ecoturismo e conservação dos recursos naturais. In: NEIMAN, Z; RABINOVICCI, A. Turismo e meio ambiente no Brasil. Barueri, São Paulo: Ed.

Manole, 2010. p. 84-104.

PRIMACK, R. B.; RODRIGUES, E. Biologia da Conservação. Rio de Janeiro: Planta, 2001.

SOARES, M.L.G., CHAVES, F.O., CORRÊA, F.M. E SILVA JR., C. M. G. Diversidade Estrutural de Bosques de Mangue e sua Relação com Distúrbios de Origem Antrópica: o caso da Baia de Guanabara (Rio de Janeiro), Anuário do Instituto de Geociências - UFRJ, 26: p.101-116. 2003.

UNESCO. Rapport final du group d'experts sur le project 13: la perception de la qualité du milieu dans le Proramme sur l'homme et la biosphére (MAB). Unesco, Paris (Série des rapports du MAB 9). 1973. 